\title{
Friction Coefficient of Bare Foot Sliding Against Marble Flooring Tiles
}

\author{
W. Y. Ali \\ Faculty of Engineering, Taif University, Al-Taif, Saudi Arabia \\ wahyos@hotmail.com
}

\begin{abstract}
The present work investigates the effect of the detergent content diluted in the washing water on the friction coefficient of bare foot sliding against marble tiles during walking. Two types of deodorizers as well as a disinfectant were used. The static friction coefficient of bare foot at wet and dry sliding conditions was measured. The tested detergent was added into water in concentration varied from 0 to $0.5 \mathrm{vol}$. $\%$. The water was diluted by disinfectant of 2.0 vol. \% concentration before the tested tiles were replenished by the dilution. Experiments were carried out using a test rig designed and manufactured for these tests. Loads were applied up to $700 \mathrm{~N}$. The normal and friction forces were measured to determine the static friction coefficient under wet and dry sliding conditions.

Based on the experimental results, it was found that friction coefficient decreased with increasing the deodorizers content, where values of friction coefficient were relatively low so that the sliding conditions could be classified as unsafe walking. After drying, friction coefficient displayed relatively higher values than that observed by wet sliding. Besides, it was observed that friction coefficient decreased with increasing detergent content. The friction values were higher than that displayed by deodorizers. After drying, friction coefficient increased up to maximum then decreased with increasing detergent content. Diluting water by detergent and deodorizers showed drastic friction decrease for deodorizer (I). Significant friction increase was observed for deodorizer (II) at wet sliding condition. After drying, friction increased up to 0.7 at $200 \mathrm{~N}$ load.
\end{abstract}

Keywords: Static friction coefficient, disinfectant, deodorizer, detergent, bare foot, marble flooring tiles. 


\section{Introduction}

Low static friction coefficient related to bare foot sliding on flooring tiles has been hypothesized to be a major factor in occupational walking accidents. The static friction coefficient of bare foot and foot wearing socks walking against wet and dry marble floor tiles used in Tawaf yard and Massaa as well as in Halls, Entrances and Passages areas in AlHaram in Makkah was tested ${ }^{[1]}$. Eight different types of detergent were used. It was found that tiles of Massaa displayed the highest friction values which reached 0.8, while tiles of the Halls displayed the lowest friction at dry sliding. For foot wearing cotton socks, it was noticed that the tiles of Massaa displayed the highest friction values followed by the tiles of Tawaf and Halls at dry sliding. The sliding condition ranged between very slip-resistant and slip-resistant. In the presence of water, friction coefficient displayed relatively higher friction values than that observed at dry sliding.

There is an increasing demand to study the static friction coefficient displayed by bare foot walking against the flooring of AlHaram in Makkah. Due to the huge number of visitors during 24 hours a day, the cleaning, deodorizing and disinfecting processes are performed continuously to remove the fatty acids transferred from bare feet of the visitors as well as the dust accumulated on the flooring. Slip resistance of flooring materials is one of the major factors affecting bare foot walking. The effect of the detergent content on the static friction coefficient of bare foot walking against wet and dry marble floor tiles used in Tawaf yard (A) and Massaa (B) as well as in halls and passages (C) in AlHaram in Makkah was tested ${ }^{[2]}$. The experimental results obtained under the selected applied normal loads showed that, at wet sliding of bare foot against (A) type tiles, friction coefficient decreased down to minimum then slightly increased with increasing detergent content. The highest friction values were displayed at 0.031 vol. \% detergent content. After drying, friction coefficient increased up to maximum then decreased with increasing detergent content. Maximum values of friction coefficient were $0.72,0.5$ and 0.46 at normal loads of 200,400 and $600 \mathrm{~N}$, obtained at 0.25 vol. $\%$ detergent content.

The effect of the cotton content of socks on the frictional behaviour of foot during walking was studied ${ }^{[3]}$. The static friction coefficient 
displayed by foot wearing socks of different cotton content under dry, water and water detergent mixture lubricated sliding conditions was investigated. Marble floor tiles used in Tawaf yard (A) and Massaa (B) as well as in halls and passages (C) in Al-Haram in Makkah were tested. Seven different socks made from the blend of cotton and polyamide were used in the measurements of the static friction coefficient. It was found that friction coefficient increased with increasing the cotton content in socks, where polyamide socks displayed the lowest friction and cotton socks displayed the highest one. The highest friction coefficient was displayed by Massaa flooring tiles followed by Tawaf and Halls tiles. For foot wearing socks, water lubricated sliding gave relatively higher friction values than dry sliding. It was concluded that appropriate shoes and insoles are not enough and attention must also be paid to socks ${ }^{[4,5]}$. Hosiery helps to remove perspiration from the skin, regulate foot temperature, provide pressure relief, and protect the skin from abrasion. The static and dynamic coefficients of friction between skin and socks and the effect of sock wearing on foot biomechanical response were not studied in terms of their frictional properties ${ }^{[6,7]}$. It is estimated that an individual takes about 8000 - 10,000 steps a day. During walking, foot presses and rubs against flooring materials.

It was reported that ${ }^{[8,9]}$, the friction coefficient between skin and Teflon fabric can be as low as 0.04 while that between skin and cotton fabric is as high as 0.54 . Wearing sock can reduce friction and allow the foot to slip on the flooring ${ }^{[10]}$. Wearing sock with low friction against foot skin is more effective in reducing shear on the skin than the sock with low friction against the insole ${ }^{[11]}$, hence is able to reduce the risk of developing blisters and ulcers. Friction between the insole, sock and foot has significant impact on the perception of comfort and the risk of injury of the wearers. Low friction allows the foot to move easily in the shoe. However, excessive movement can result in feeling of insecurity and may generate pressure and rubbing between the top and upper part of the foot and the shoe ${ }^{[12]}$. Too low friction in the both interfaces may lead to excessive movement of foot in shoe and induces discomfort feeling of insecurity. It was found that the difference of friction coefficient among interfaces provide insight into where slip occurs ${ }^{[13]}$. It was recommended to set low friction on one side to allow foot sliding, and high friction on 
the other side to provide appropriate level of resistance to avoid excessive movement.

It was found that wearing sock of low friction against the insole to allow more relative sliding between the plantar foot and footwear was found to reduce the shear force significantly ${ }^{[14]}$. Socks are able to change the frictional properties between the foot-shoe interface. Abrasion of the foot skin can be avoided by reducing the shear between the contact interfaces with the use of socks made from textile fibers of low frictional coefficients ${ }^{[15]}$. The mechanical effect of sock with different frictional properties on foot was investigated by finite element models ${ }^{[16,17]}$. Wearing sock can reduce friction and allow the foot to slip on the insole, hence to reducing the shear. It was reported that by using the Teflon fiber to the sock soles to impart an extremely low friction value, the socks reduced the occurrences of blister by around 90 vol. \% in athletes ${ }^{[18]}$. Shear is possibly a main mechanical risk factor of blister development. Therefore, reduction of shear is crucial in preventing the foot lesion development.

Slip resistance of flooring materials is one of the major environmental factors affecting walking and materials handling behaviors. Floor slipperiness may be quantified using the static and dynamic friction coefficient ${ }^{[19]}$. Certain values of friction coefficient were recommended as the slip-resistant standard for unloaded, normal walking conditions ${ }^{[20,21]}$. Relatively higher static and dynamic friction coefficient values may be required for safe walking when handling loads. Coefficients of friction were measured periodically over a period of 30 months on the surfaces of five types of floor coverings in a new sport complex ${ }^{[22]}$. The changes in the surface properties and frictional characteristics of floor coverings can be expected in practical use because they are subject to mechanical wear, ageing, soiling and maintenance ${ }^{[23]}$. Surface changes through mechanical wear range from smoothing to roughening, depending on flooring material and surface characteristics. Surface roughness is known to be a key factor in determining the slip resistance of floors ${ }^{[24,25]}$.

The effect of surface roughness of ceramic on the friction coefficient when rubber and leather are sliding against it was investigated ${ }^{[26]}$. The test results showed that, friction coefficient decreased down to 
minimum then increased with increasing the surface roughness of the ceramic surface. It was observed that, dry sliding of the rubber test specimens displayed the highest value of friction coefficient ${ }^{[27-29]}$. For water lubricated ceramics, the value of the friction coefficient decreased compared to dry sliding. For oil lubricated ceramic, friction coefficient decreased with increasing height of the grooves introduced in the rubber specimens. Besides, diluting oil by water displayed values of friction much lower than that observed for oil lubricated condition. As for ceramic lubricated by water and soap and contaminated by sand, friction coefficient increased significantly compared to the sliding conditions of water and soap only. In the presence of oil and sand on the sliding surface, the friction slightly increased.

In the present work, the effect of content of the deodorizer as well as detergent diluted in the washing water on the friction coefficient displayed by bare foot sliding against marble tiles during walking is discussed. The static friction coefficient displayed by bare foot at wet and after drying sliding conditions was measured.

\section{Experimental}

Experiments were carried out using a test rig designed and manufactured to measure the friction coefficient between the foot and the tested flooring tiles through measuring the friction and normal forces (Fig. 1). The details of the test rig and the tested flooring tiles are illustrated, ${ }^{[1]}$. The tested detergents and deodorizers (I) and (II) were added to the water in concentration varied from 0 to 0.5 vol. \%. The disinfectant used in the experiments was added to water in concentration of 2.0 vol. \%. The details of the disinfectants, deodorizers and detergents are illustrated in Table 1.

Table 1. The disinfectants, deodorizers and detergents used in the experiments.

\begin{tabular}{|l|l|}
\hline Type & Characteristics \\
\hline A & Anti Bacterial Anti Septic Disinfectant \\
\hline B & Disinfectant Pine (Deodorizer I) \\
\hline C & Highly Perfumed Cleaner (Deodorizer II) \\
\hline D & Detergent for Fat and oil removal \\
\hline
\end{tabular}




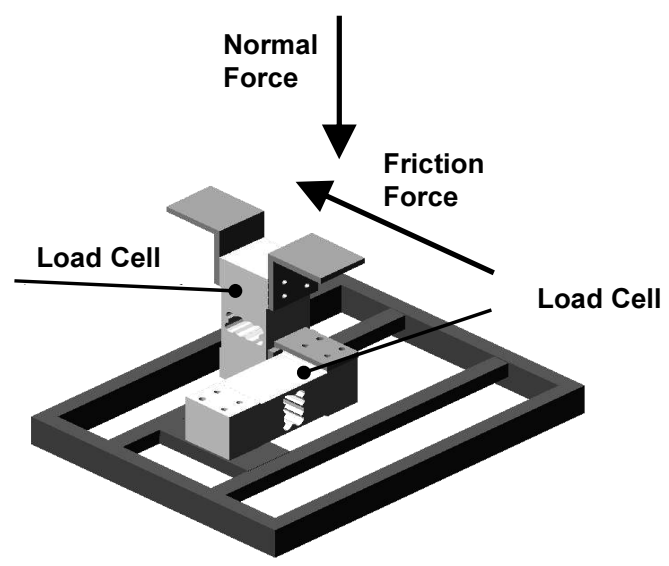

Fig. 1. Arrangement of the test rig.

The dilution was replenished on the tested flooring tiles, where the amount for each replenishment was $10 \mathrm{ml}$ to form consistent water film covering the sliding surface. After the wet test, the tiles were air dried and the friction test was carried out. After each measurement, all contaminants were removed from the flooring materials using absorbent papers. The flooring materials were then rinsed using water and blown using hair dryer after the cleaning process. Every test was repeated five times and the average values were considered. Tests were carried out at different values of load exerted by foot. In the present work, the results of three selected values of load of 200, 400 and $600 \mathrm{~N}$, which represent the average weights of the children, women and men, were considered.

\section{Results and Discussion}

The effect of the deodorizer (I) on the static friction coefficient displayed by bare foot sliding against wet marble tiles is shown in Fig. 2. Friction coefficient decreased with increasing the deodorizer content. The friction decrease may be attributed to ability of deodorizer molecules to adhere to the sliding surfaces and hence facilitate the sliding process. Furthermore, it was observed that as the load increased friction coefficient decreased due to the decrease of the hysteric component of friction due to the adhesive junctions stretch, rupture and relax. It is noted that values of friction coefficient were relatively low so that the sliding conditions can be hypothesized to be a major factor in occupational slip accidents. At 0.5 vol. \% deodorizer content the values 
of friction coefficient were $0.21,0.17$ and 0.15 at 200,400 and $600 \mathrm{~N}$ respectively. Those values indicate unsure walking.

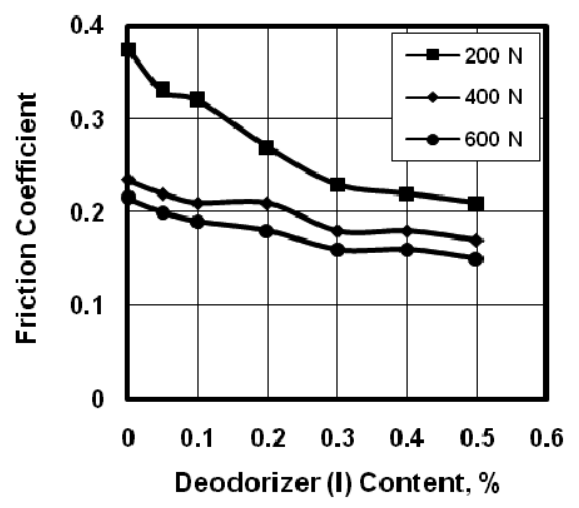

Fig. 2. Friction coefficient displayed by deodorizer (I).

After drying, friction coefficient significantly increased (Fig. 3). Friction coefficient displayed relatively higher values than that observed by wet sliding. At load of $200 \mathrm{~N}$, friction coefficient showed maximum value of 0.6 at deodorizer content up to 0.2 vol. \%. It seems that a film of the deodorizer molecules adhered to the sliding surface preventing the contaminants to stick to the sliding surface. As the deodorizer content exceeded certain concentration $(0.2$ vol. \%) the adherence process might be disturbed due the attractive forces between the molecules themselves and between the molecules and the sliding surfaces. It is clearly shown that the increase of friction coefficient offered by deodorizer was much effective after drying. Friction coefficient displayed by the sliding of bare foot against ceramics wetted by deodorizer (II), Fig. 4, showed similar trend like deodorizer (I).

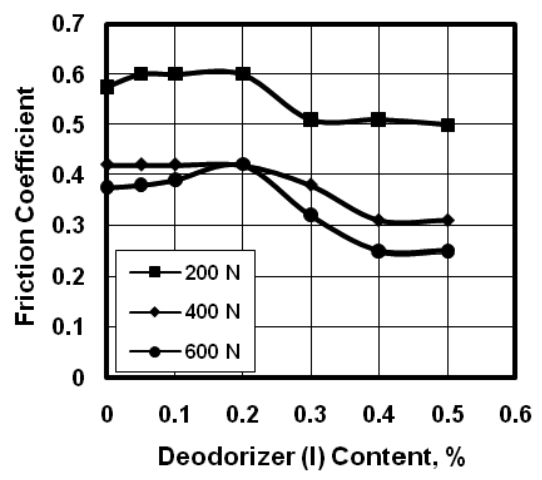

Fig. 3. Friction coefficient displayed by deodorizer (I) after drying. 


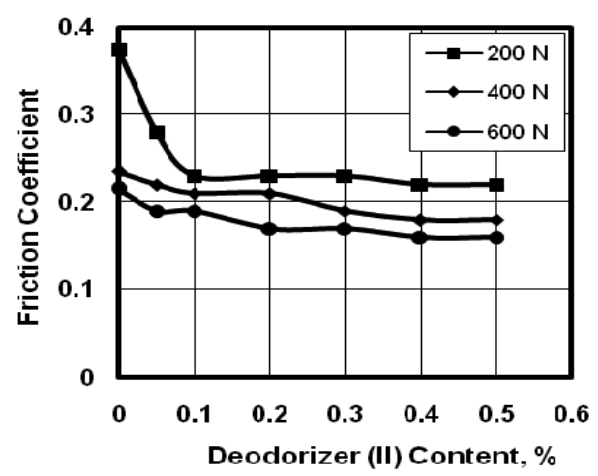

Fig. 4. Friction coefficient displayed by deodorizer (II).

After drying at $200 \mathrm{~N}$ load (Fig. 5), friction coefficient increased up to maximum at deodorizer content of 0.05 vol. \% then drastically decreased with increasing deodorizer content. The maximum friction values were $0.63,0.47$ and 0.43 at loads of 200,400 and $600 \mathrm{~N}$ respectively. Those friction values were much higher than that displayed by wet sliding. As accident prevention and slip resistance point of view, those values of high friction guarantee safe walking. It seems that the deodorizer which is a formulation comprising essential constituents such as surface active agents reacted with the fatty acids of foot. The mechanism of action may be explained on the basis that when the deodorizer is dissolved or dispersed in a liquid is preferentially absorbed at the sliding surfaces, giving rise to the growth of a film of deodorizer molecules which absorb fatty acids and perspiration from the skin of bare foot so that the contact remains between foot and flooring.

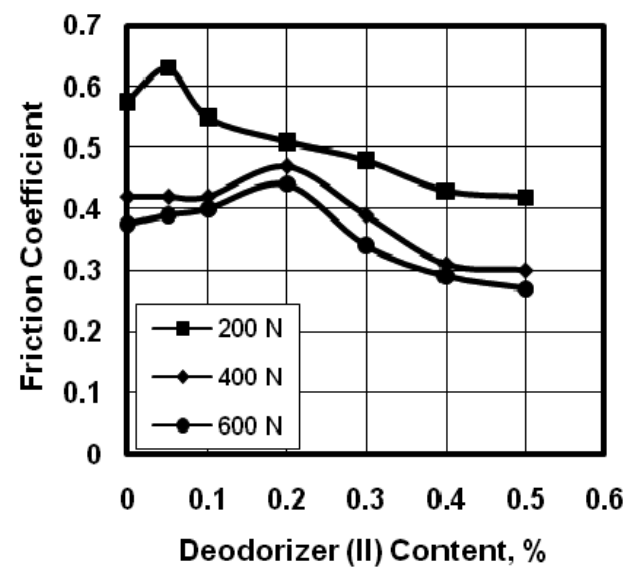

Fig. 5. Friction coefficient displayed by deodorizer (II) after drying. 
The effect of the tested detergent on the static friction coefficient is shown in Fig. $6-11$. Sliding of bare foot against the wet tiles showed that friction coefficient decreased with increasing detergent content (Fig. 6). The friction values were higher than that displayed by the previous condition in Fig. 2 and 4. This increase in friction could be attributed to effectiveness of the Cleaner (I). After drying, Fig. 7, friction coefficient increased up to maximum then decreased with increasing detergent content. Maximum friction values were 1.05, 1.0 and 0.93 at detergent content of 0.125 vol. $\%$ at 200,400 and $600 \mathrm{~N}$ respectively.

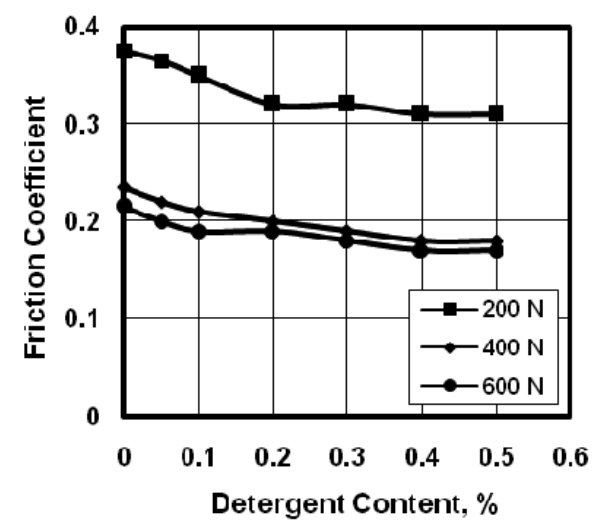

Fig. 6. Friction coefficient displayed by detergent (B).

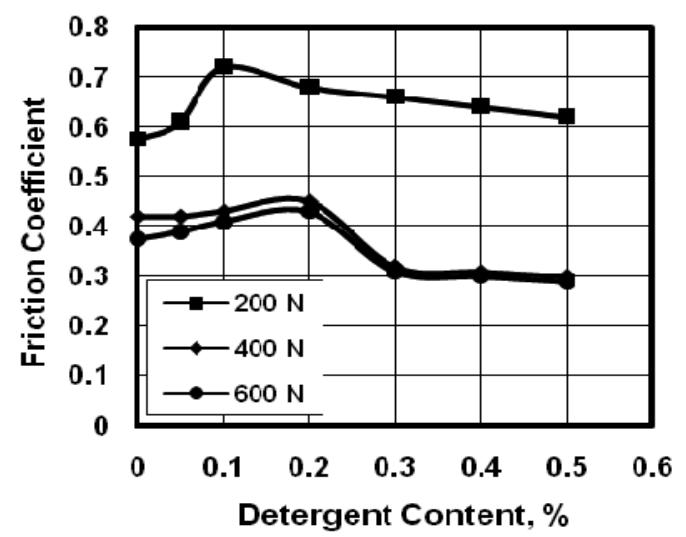

Fig. 7. Friction coefficient displayed by detergent (B) after drying. 


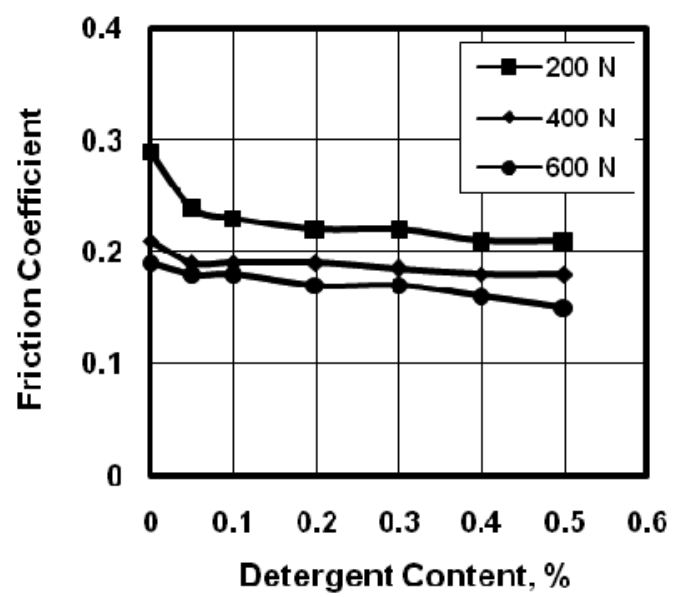

Fig. 8. Friction coefficient displayed by detergent (B) and deodorizer (I).

Diluting the water by the deodorizer (I), Fig. 8, showed drastic friction decrease compared to the condition shown in Fig. 6. Friction coefficient decreased with increasing detergent content at wet sliding. As accident prevention and slip resistance point of view, those values of relatively low friction are classified as unsafe walking. It seems that the presence of the deodorizer (I) reduced the influence of the detergent by disturbing the formation of the surface active agents that react with the fatty acids of foot. After drying, Fig. 9, friction coefficient increased, where maximum friction values were $0.66,0.45$ and 0.42 at 200, 400 and $600 \mathrm{~N}$ respectively. Maximum friction was displayed at 0.1 vol. \% detergent content. The friction increase might be attributed to two reason, the first the ability of the detergent to clean the surface, where detergents have hydrophobic or water-hating molecular chains and hydrophilic or water-loving components. The hydrophobic hydrocarbons are repelled by water, but are attracted to oil and grease. The hydrophilic end of the same molecule means that one end of the molecule will be attracted to water, while the other side is binding to oil. Then rinsing washes the detergent and soil away. The second reason is the formation of the film on the sliding surfaces consisting of detergent molecules and protecting the flooring tiles from the fatty acid and perspiration of the skin of bare foot. 


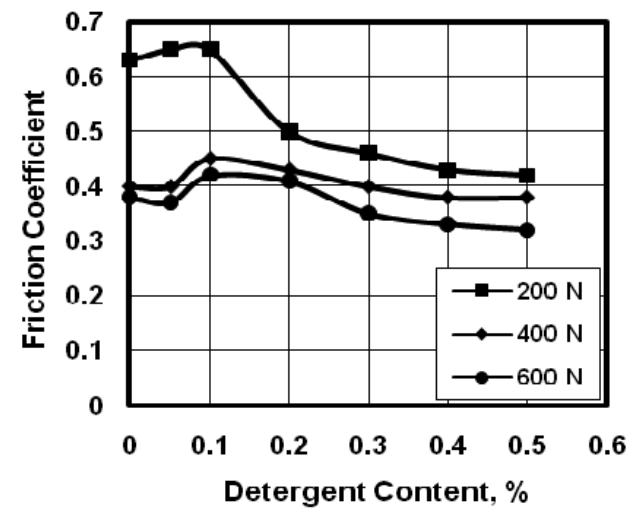

Fig. 9. Friction coefficient displayed by detergent (B) and deodorizer (I) after drying.

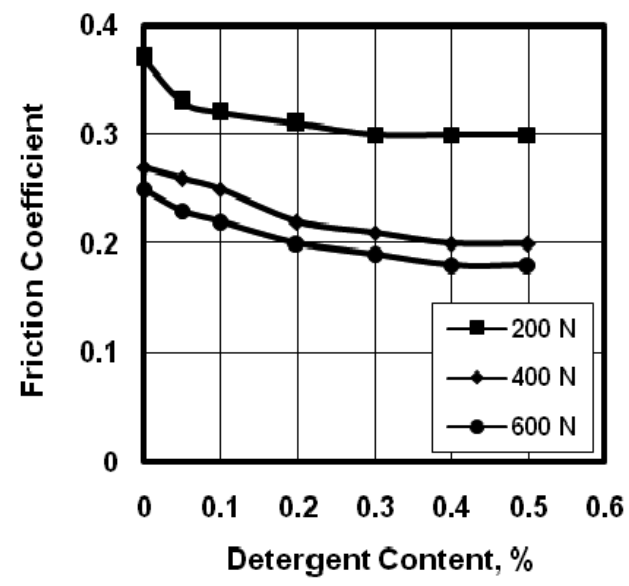

Fig. 10. Friction coefficient displayed by detergent (B) and deodorizer (II).

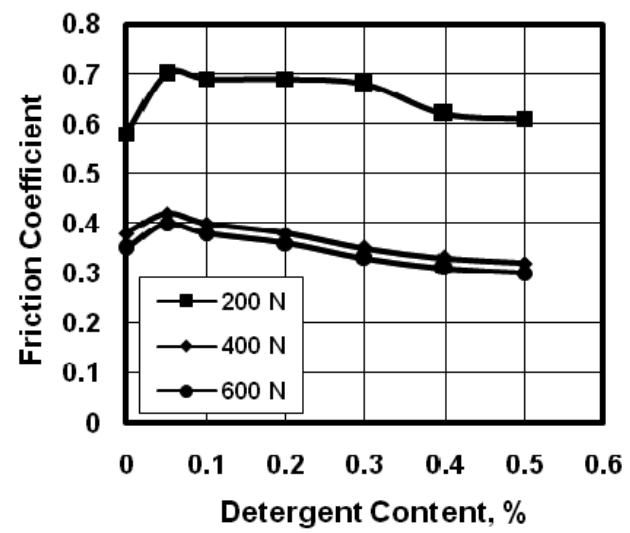

Fig. 11. Friction coefficient displayed by detergent (B) and deodorizer (II) after drying. 
Significant friction increase was observed for deodorizer (II), Fig. 10 , at wet sliding condition. At $200 \mathrm{~N}$ load, the minimum value of friction coefficient was 0.3. Based on the European standard, the sliding can be considered as very slip resistant. As the load increased to 400 and $600 \mathrm{~N}$ friction values decreased to 0.2 and 0.17 respectively which represent unsure walking. After drying, friction increased at $200 \mathrm{~N}$ load, where the highest and lowest values were 0.7 and 0.6 respectively. The friction increase may be attributed to the absorption of the detergent at the sliding surfaces (bare foot and tiles), giving rise to the growth of a film of detergent molecules which absorb fatty acids and perspiration from the skin of bare foot so that the contact remains between foot and marble tiles.

\section{Conclusions}

The present experiments provided quantitative results on the static friction coefficient displayed by bare foot sliding against the tested tiles. Furthermore, the analysis of the measured data gave information about the effectiveness of the tested detergent, deodorizers and disinfectant. A better knowledge of the mechanism of action of the cleaning fluids that influence the measurement of friction coefficient would allow their proper selection for safe walking.

Friction coefficient decreased with increasing the deodorizers content, where values of friction coefficient were relatively low so that the sliding conditions could be hypothesized to be a major factor in occupational slip accidents. After drying, friction coefficient displayed relatively higher values than that observed by wet sliding. Sliding of bare foot against the wet tiles showed that friction coefficient decreased with increasing detergent content. The friction values were higher than that displayed by deodorizers. After drying, friction coefficient increased up to maximum then decreased with increasing detergent content.

Diluting the water by detergent and deodorizers showed drastic friction decrease for deodorizer (I). As accident prevention and slip resistance point of view, those values of relatively low friction are classified as unsafe walking. Significant friction increase was observed for deodorizer (II) of $0.05 \%$ at wet sliding condition. After drying, friction increased up to 0.7 at $200 \mathrm{~N}$ load. Based on that observation, it is recommended to use deodorizer (II) of $0.05 \%$ concentration. 


\section{Acknowledgement}

The author would like to express his sincere gratitude to the University of Al -Taif for its fully funding this research project (project number 350/1430).

\section{References}

[1] Ali, W. Y., "Frictional behaviour of bare foot and foot wearing socks walking against marble flooring tiles", Under Publication (2009).

[2] Ali, W. Y., "Effect of Cleaners on the Frictional Behaviour of Bare Foot During Walking", Journal of the Egyptian Society of Tribology, 6(3) July: 13 - 25 (2009).

[3] Ali, W. Y. and Sulaimany, A., "Effect of Cotton Content of Socks on the Frictional Behaviour of Foot During Walking", Journal of the Egyptian Society of Tribology, 6(3) July: $51-64$ (2009).

[4] Mayfield, J. A., Reiber, G. E., Sanders, L. J., Janisse, D. and Pogach, L. M., "Preventive foot care in people with diabetes", Diabetes Care, 21: 2161 - 2177, (1998).

[5] Phillips, P., Evans, A. and Popplewell, P., "Diabetic foot ulcers, a guide to treatment", Am. J. Clin. Dermatol., 1: 117 - 123 (2000).

[6] Scheffler, N. M., “All about socks”, Diabetes Forecast, 54, 78: 80 - 81 (2001).

[7] Veves, A., Masson, E. A., Fernando, D. J. S. and Boulton, A. J. M., "Use of experiment padded hosiery to reduce abnormal foot pressures in diabetic neuropathy", Diabetes Care 12: 653 - 655, (1989).

[8] Buirski, D., "Just slip into something a little more comfortable", World Sports Activewear, 6: 49 - $50(2000)$.

[9] Zhang, M. and Mak, A. F. T., "In vivo skin frictional properties", Prosthet. Orthot. Int., 23: 135 - 141 (1999).

[10] Hosein, R. and Lord, M., "A study of in-shoe plantar shear in normals", Clin. Biomech., 15: $46-53$ (2000).

[11] Xiao-Qun Dai, Yi Li and Ming Zhang, Jason Tak-Man Cheung, "Effect of sock on biomechanical responses of foot during walking", Clinical Biomechanics, 21: 314-321 (2006).

[12] Draper, D., "Coming down to earth", World Sports Activewear, 5: 53 - 55 (1999).

[13] Sanders, J.E., Greve, J.M., Mitchell, S.B. and Zachariah, S.G., "Material properties of commonly-used interface materials and their static coefficient of friction with skin and socks", J. Rehab. Res. Dev., 35: 161 - 176 (1998).

[14] Dai, X., Li Y., Zhang, M. and Cheung, J., "Effect of sock on biomechanical responses of foot during walking", Clinical Biomechanics, 21: 314 - 321 (2006).

[15] Delporte, C., "New socks offer relief, blister guard system with Teflon reduces friction between foot and sock", America's Textiles International , 26, K/A 10 (1997).

[16] Thomas, V. J., Patial, K. M. and Radhakrishnan, S., "Three-dimensional stress analysis for the mechanics of plantar ulcers in diabetic neuropathy", Med. Biol. Eng. Comput., 42: 230 - 235 (2004).

[17] Gefen, A., "Plantar soft tissue loading under the medial metatarsals in the standing diabetic foot", Med. Eng. Phys. 25, pp. 491 - 499, (2003). 
[18] Jacob, S. and Patil, M. K., "Stress analysis in three-dimensional foot models of normal and diabetic neuropathy", Front. Med. Biol. Eng., 9: 211 - 227 (1999).

[19] Li, K. W., Yu, R. and Han, X. L., "Physiological and psychophysical responses in handling maximum acceptable weights under different footwear-floor friction conditions", Applied Ergonomics, 38: 259 - 265 (2007).

[20] Miller, J. M., "'Slippery" work surface: toward a performance definition and quantitative coefficient of friction criteria", J. Saf. Res., 14: 145 - 158 (1983).

[21] Grönqvist, R., "Mechanisms of friction and assessment of slip resistance of new and used footwear soles on contaminated floors", Ergonomics, 38: 224 - 241 (1995).

[22] Derler, S., Kausch, F. and Huber, R., "Systematic patterns and random fluctuations in time series of coefficients of friction measured on floor surfaces", Safety Science, 43: 391 - 405 (2005).

[23] Leclercq, S. and Saulnier, H., "Floor slip resistance changes in food sector workshops: prevailing role played by fouling", Safety Science, 40: 659 - 673 (2002).

[24] Chang, W.-R., Kim, I.-J., Manning, D.P., Bunterngchit, Y., "The role of surface roughness in the measurement of slipperiness", Ergonomics 44, pp. 1200 - 1216, (2001).

[25] Chang, W.-R., Li, K.W., Huang, Y. H., Filiaggi, A. and Courtney, T.K., "Assessing floor slipperiness in fast-food restaurants in Taiwan using objective and subjective measures", Applied Ergonomics, 35: 401 - 408 (2004).

[26] Ezzat, F. H., Abdel-Jaber, G. T. and Ali, W. Y., "Dry Sliding of Rubber on Glazed Ceramic Tiles", KGK . November 2008 , pp: 576 - 579 (2008).

[27] Samy, A. M., Mahmoud, M. M., Khashaba, M. I. and Ali, W. Y., "Friction of Rubber Sliding Against Ceramics, I. "Dry And Water Lubricated Conditions", KGK Kautschuk Gummi Kunststoffe 60. Jahrgang, Nr 607, Juni 2007, pp: 322 - 327 (2007).

[28] Samy, A. M., Mahmoud, M. M., Khashaba, M. I. and Ali, W. Y., "Friction of Rubber Sliding Against Ceramics, II. Oil And Oil Diluted By Water Lubricated Conditions", KGK Kautschuk Gummi Kunststoffe 60. Jahrgang, Nr 607, December 2007, pp: 693 - 696 (2007).

[29] Samy, A. M., Mahmoud, M. M., Khashaba, M. I. and Ali, W. Y., "Friction of Rubber Sliding Against Ceramics, III. Sand Contaminating The Lubricating Fluids", KGK Kautschuk Gummi Kunststoffe 61. Jahrgang, Nr 608, January 2008, pp: 43 - 48 (2008). 


\section{معامل الاحتكاك بين القدم العارية وبلاط الأرضيات الرخامية}

\section{وحيد بسري علي}

كلبة الهندسة، جامعة الطائف، الطائف، المدلكة العربية السعودية

المستخلص: يدرس هذا البحث تأثير تركيز سائل التنظيف فى ماء

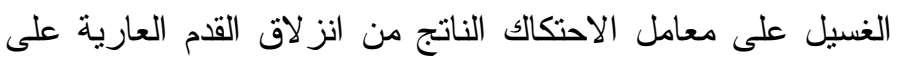

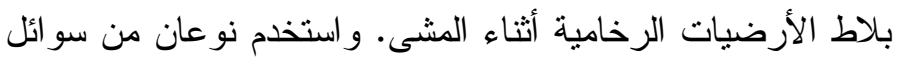
التعطير وسائل مطهر، بالإضافة إلى سائل التظيف المقترح. أضيف كل من سائل التنظيف وسائلى التعطير إلى الماء بنسبة الإضى متغيرة تصل إلى 0, •٪، كما أضيف السائل المطهر بنسبة ثابتة هى •, ؟ ث بللت البلاطات الرخامية المختبرة بالمخلوط.

أجريت التجارب باستخدام جهاز اختبار صمم لقياس معامل الاحتكالك بين المطاط ومو اد الأرضيات عن طريق قياس قوة الاحتكالك و القوة الرأسية الناتجة من وزن جسم الإنسان لتحديد معامل الاحتكالك

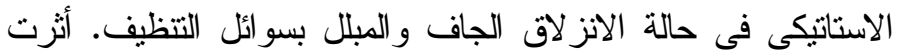
القوة الرأسية عن طريق القدم، وبلغت أقصى قيمة لها ل . > نيونت. بينت التجارب أن معامل الاحتكاك قد قل بزيادة ثركيز سوائل التعطير، حيث كانت قيم معامل الإحتكاك منخفضة، لدرجة أن المشى فى هذه الحالة يصنف على أنه غير آمن. بعد تجفيف

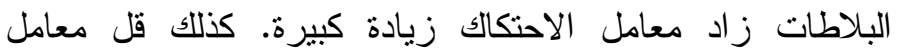
الاحتكالك مع زيادة تركيز سائل التنظيف، ولكن كانت قيمته أعلى زئى من حالة استخدام سوائل التعطير • وبعد التجفيف زاد لاد معامل الاحتكاك إلى قيمة قصوى، ثم قل بعد ذلك مع زيادة نركيز سائل

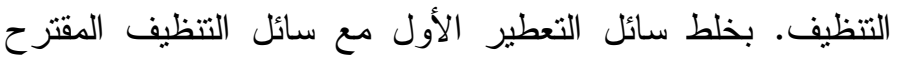


انخفض معامل الاحتكاك انخفاضا كبيرًا، إلا أنه زاد مع سائل

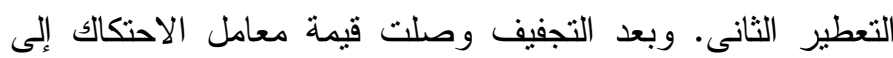

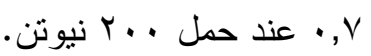

